\title{
O ACESSO À JUSTIÇA NAS ORGANIZAÇÕES SOCIAIS COMPLEXAS COMO CONCRETIZAÇÃO DO PRINCÍPIO DA DIGNIDADE DA PESSOA HUMANA
}

Ivan Aparecido Ruiz ${ }^{1}$

Taís Zanini de Sá Duarte Nunes ${ }^{2}$

RUIZ, I. A.; NUNES, T. Z. de S. D. O acesso à justiça nas organizações sociais complexas como concretização do princípio da dignidade da pessoa humana. Rev. Ciênc. Juríd. Soc. UNIPAR. Umuarama. v. 17, n. 2 p. 129-153, jul./dez. 2014

RESUMO: O presente artigo visa retratar a importância dos métodos autocompositivos na sociedade contemporânea, tendo em vista que concedem à pessoa a oportunidade de refletir sobre o conflito de interesses e participar ativamente na solução do mesmo, proporcionando uma verdadeira pacificação social. Dentre os novos direitos provocados pela complexidade de relações da sociedade de massa e rede, o princípio da dignidade da pessoa humana serve de fundamento para o Estado Democrático de Direito, gerando, também, a necessidade de garantir, por meio do acesso à justiça, os direitos fundamentais da pessoa. Aborda-se, de forma sucinta, a origem da sociedade de massa e de rede, bem como algumas das suas implicações sociais resultando, principalmente, na alienação do ser humano, que por algumas décadas acreditou que o Poder Judiciário fosse o detentor do monopólio de solução de conflitos.

PALAVRAS-CHAVE: Acesso à justiça; Princípio da dignidade da pessoa humana; ADRs.

\section{INTRODUÇÃO}

Os séculos XIX e XX foram marcados pela profunda decadência axio-

DOI: https://doi.org/10.25110/rcjs.v17i2.2014.5398

${ }^{1}$ Pós-doutor em Direito pela Faculdade de Direito da Universidade de Lisboa - FDUL, Doutor em Direito das Relações Sociais pela Pontifícia Universidade Católica de São Paulo - PUC/SP, Mestre em Direito das Relações Sociais pela Universidade Estadual de Londrina - UEL/PR, Professor Associado do Curso de Graduação em Direito da Universidade Estadual de Maringá - UEM/PR e, também, do Programa de Mestrado em Ciências Jurídicas do Centro Universitário de Maringá - CESUMAR. Advogado no Paraná.

${ }^{2}$ Mestranda em ciências jurídicas pelo Centro Universitário de Maringá - CESUMAR. Especialista em Direito do Estado e Relações Sociais pela Universidade Católica Dom Bosco - PUC de Campo Grande/MS e Direito Tributário pela Universidade Anhanguera - LFG de Maringá/PR. 
lógica do ser humano, por isso aprouve aos Tratados Internacionais ${ }^{3}{ }^{4}$ e Constituições de vários países ${ }^{5}{ }^{6}{ }_{-}{ }^{7}$ promover a pessoa como uma pessoa detentora de dignidade, a fim de que seus direitos naturais, humanos e fundamentais ${ }^{8}$ fossem respeitados pelo Estado e pelas demais pessoas.

O pós-Segunda Guerra Mundial e fim do Nazifascismo são marcados por vários movimentos em prol da proteção da pessoa, tais como o personalismo ético de Jackes Maritain, defensor do humanismo integral e colaborador no texto da Declaração Universal de Direitos Humanos de 1948.

Decorrente desses movimentos culturais, sociais e filosóficos nasce o Estado Democrático de Direito ${ }^{9}$, no qual a participação da sociedade é essencial,

${ }^{3}$ Confira-se o artigo $1^{\circ}$ da Declaração Universal dos Direitos do Homem: "Artigo $1^{\circ}$. Todos os seres humanos nascem livres e iguais em dignidade e em direitos. Dotados de razão e de consciência, devem agir uns para com os outros em espírito de fraternidade".

${ }^{4}$ Confira-se o art. $1^{\circ}$, números 1 e 2, do Pacto de São José da Costa Rica, aprovado pelo Brasil, por força do Decreto n. 678, de 6 de novembro de 1992 (Promulga a Convenção Americana sobre Direitos Humanos (Pacto de São José da Costa Rica), com o seguinte teor: "ARTIGO 5 Direito à Integridade Pessoal 1.Toda pessoa tem o direito de que se respeito sua integridade física, psíquica e moral. 2. Ninguém deve ser submetido a torturas, nem a penas ou tratos cruéis, desumanos ou degradantes. Toda pessoa privada da liberdade deve ser tratada com o respeito devido à dignidade inerente ao ser humano. [...]".

${ }^{5}$ A CONSTITUIÇÃO DA REPÚBLICA PORTUGUESA, nos Princípios fundamentais, no Artigo 1. ${ }^{\circ}$ (República Portuguesa), estabelece: "Princípios fundamentais Artigo 1. ${ }^{\circ}$ (República Portuguesa) Portugal é uma República soberana, baseada na dignidade da pessoa humana e na vontade popular e empenhada na construção de uma sociedade livre, justa e solidária".

${ }^{6}$ Vide o art. $3^{\circ}$. da COSTITUZIONE DELLA REPUBBLICA ITALIANA: "Art. 3 Tutti i cittadini hanno pari dignità sociale e sono eguali davanti alla legge, senza distinzione di sesso, di razza, di lingua, di religione, di opinioni politiche, di condizioni personali e sociali. È compito della Repubblica rimuovere gli ostacoli di ordine economico e sociale, che, limitando di fatto la libertà e la uguaglianza dei cittadini, impediscono il pieno sviluppo della persona umana e l'effettiva partecipazione di tutti i lavoratori all'organizzazione politica, economica e sociale del Paese".

${ }^{7}$ Confira-se, a propósito, o art. $1^{\circ}$, inc. III, da Constituição da República Federativa do Brasil de 1988, quando do tratamento Dos Princípios Fundamentais, in verbis: “Art. $1^{\circ}$. A República Federativa do Brasil, formada pela união indissolúvel dos Estados e Municípios e do Distrito Federal, constitui-se em Estado Democrático de Direito e tem como fundamentos: [...] III - a dignidade da pessoa humana; $[\ldots]^{\prime \prime}$.

${ }^{8}$ Acerca dos Direitos Humanos e Direitos Fundamentais Origens, conceituações e distinções, fundamentação, consulte BEZERRA, Cesar Santos. Temas atuais de direitos fundamentais. 2. ed. revisada e ampliada. Ilhéus: Editus/UESC, 2007, p. 13 a 50.

${ }^{9}$ Este modelo de Estado foi adotado pelo Brasil, conforme se vê do Preâmbulo da Constituição da República Federativa do Brasil de 1988 e, particularmente, pelo art. 1º, caput, inserto no Título que trata DOS DIREITOS FUNDAMENTAIS. Confira-se: "PREÂMBULO Nós, representantes do povo brasileiro, reunidos em Assembléia Nacional Constituinte para instituir um Estado Democrático, destinado a assegurar o exercício dos direitos sociais e individuais, a liberdade, a segurança, o bem-estar, o desenvolvimento, a igualdade e a justiça como valores supremos de uma sociedade fraterna, pluralista e sem preconceitos, fundada na harmonia social e comprometida, na ordem interna e internacional, com a solução pacífica das controvérsias, promulgamos, sob a proteção de Deus, a seguinte CONSTITUIÇÃO DA REPÚBLICA FEDERATIVA DO BRASIL.TÍTULO I DOS

Rev. Ciênc. Juríd. Soc. UNIPAR, v. 17, n. 2, p. 129-153, jul./dez. 2014 
além de que não visa apenas elencar direitos, mas, também, garanti-los de forma efetiva com a criação de diversos instrumentos processuais e constitucionais.

Dessa forma, a sociedade passou a buscar no Estado a concretização de seus direitos fundamentais, tendo em vista o monopólio judicial estatal com a inibição da autotutela - prevista e permitida somente em casos excepcionais ${ }^{10}-\mathrm{e}$ o princípio da inafastabilidade do Poder Judiciário (BRASIL, 1988).

Em meados da década de 50, em vários países, aconteceram movimentos que visavam promover o acesso igualitário ao Poder Judiciário, denominados por Mauro Capelletti de "ondas". Eram ações ou programas estatais que objetivavam dar a todos um tratamento igualitário de acesso ao Poder Judiciário, tanto econômica quanto tecnicamente.

Essas "ondas" ampliaram o acesso ao Poder Judiciário de forma que, atualmente, grande parte dos países ocidentais tem, no Poder Judiciário, a morosidade e o alto custo como características das quais não conseguem se desvencilhar em virtude do elevado e infindável número de demandas.

Lamentavelmente, o Poder Judiciário, com sua estrutura, não estava preparado para a rápida e complexa evolução das relações sociais, menos ainda para a cultura litigiosa que se instaurou na sociedade, levando as pessoas a crerem que é dever do Estado dar-lhes solução para todo tipo de conflito de interesses.

A procura desenfreada pelo Poder Judiciário gerou uma crise mundial nesse setor, a qual inclui, em todo o mundo, a sobrecarga de processos nos tribunais, a morosidade do processo em fases nevrálgicas, a difícil efetividade do direito reconhecido, a burocratização dos juízes, a complicação procedimental, o alto custo, etc. O problema da morosidade na entrega da prestação jurisdicional é assunto da pauta do dia, tanto para os doutrinadores, quanto para o legislador, bem como para o próprio Poder Judiciário. Isso tanto é verdade, que o tema é recorrente na doutrina e, por consequência, nas obras jurídicas, não escapando também desse contexto, as decisões judiciais.

PRINCÍPIOS FUNDAMENTAISArt. $1^{\circ}$. A República Federativa do Brasil, formada pela união indissolúvel dos Estados e Municípios e do Distrito Federal, constitui-se em Estado Democrático de Direito e tem como fundamentos: I - a soberania; II - a cidadania; III - a dignidade da pessoa humana; IV - os valores sociais do trabalho e da livre iniciativa; V - o pluralismo político. Parágrafo único. Todo o poder emana do povo, que o exerce por meio de representantes eleitos ou diretamente, nos termos desta Constituição". (original sem os itálicos).

${ }^{10}$ Confira-se, por exemplo, o art. 1210, $\S 1^{\circ}$., do Código Civil brasileiro de 2002, in verbis: "Art. 1.210. O possuidor tem direito a ser mantido na posse em caso de turbação, restituído no de esbulho, e segurado de violência iminente, se tiver justo receio de ser molestado. $\S 1^{\circ}$. O possuidor turbado, ou esbulhado, poderá manter-se ou restituir-se por sua própria força, contanto que o faça logo; os atos de defesa, ou de desforço, não podem ir além do indispensável à manutenção, ou restituição da posse. $\S 2^{\circ}$. Não obsta à manutenção ou reintegração na posse a alegação de propriedade, ou de outro direito sobre a coisa". (original sem os itálicos). 
Este caminho levou-nos, como sociedade, a uma nova realidade: a de que a pacificação social não pode ser encarada como um dever único e exclusivo do Estado, o qual nem sempre consegue proporcionar uma solução efetiva e satisfatória ante a diversidade e complexidade das relações; ela deve ser proporcionada por um trabalho em conjunto com outros organismos da sociedade. É o que se pretende enfocar nesse estudo, como objetivo. Esta trajetória tem resultado no retorno aos métodos autocompositivos de solução de conflitos de interesses, que, no ver de processualistas e juristas que se ocupam com o estudo da matéria, é uma das saídas para o "desafogamento", o descongestionamento do Poder Judiciário e para a efetividade do acesso à justiça.

\section{O SURGIMENTO DAS SOCIEDADES DE MASSA E DE REDE E SUAS IMPLICAÇÕES SOCIAIS}

Segundo a antropologia, a sociedade contemporânea caracteriza-se, principalmente, pela complexidade de suas relações, diferenciando-se das sociedades simples (primitivas) e antigas (arcaicas), não devendo ser confundida com o próprio Estado, embora seja utilizada muitas vezes como sinônimo. Assim, os padrões sociais estão intimamente ligados ao Direito, pois são eles que ditam as regras de convivência social. É o direito visto, sob um aspecto sociológico, como forma de ordenamento social. Para os autores Assis, Kumpel e Serafim: "Os padrões sociais constituem, portanto, modelos de comportamento resultantes do processo de construção da realidade e modelam ou padronizam as relações que se estabelecem entre os indivíduos" (ASSIS et al., 2012, p. 360).

As mudanças sociais, culturais e econômicas constroem o Direito conforme o conjunto de regras e de valores adotados pelas pessoas que compõem determinada sociedade, em determinado momento histórico, gerando um controle, também jurídico. Desta forma, os sistemas jurídicos são padrões sociais de comportamento vez que incutem nas normas, princípios e regras jurídicas positivas ou negativas, os valores predominantes na sociedade, os quais devem ser seguidos por todos quando se vivencia um Estado de Direito (Id. Ibid, p. 361).

As décadas de 1950 e 1990 são marcadas por profundas mudanças decorrentes dos avanços da indústria e tecnologia, principalmente dos meios de comunicação, gerando novos direitos e a necessidade de novos instrumentos para garanti-los e dar-lhes efetividade em uma sociedade de massa e de rede.

A sociedade de massa origina-se a partir da Segunda Revolução Industrial, ocorrida entre 1850 a 1870, tendo em vista que a mesma provocou a aceleração do processo de urbanização na Europa e nos EUA, gerando um grande crescimento populacional e das cidades. Dentre os vários fatores que aceleraram o crescimento urbano e o êxodo rural, Fabiana Scoleso (2014) aponta os seguin- 
tes:

a) Melhoria da alimentação: período em que houve uma expansão mundial das áreas agrícolas, com a mecanização da agricultura e o uso de fertilizantes, que permitiram ampliar a produtividade do solo. Destaca-se, também, a criação das indústrias de conservas, que foram decisivas para assegurar o abastecimento de populações cada vez mais numerosas; as experiências com conservas datam do Século XVIII, mas só no Século XIX essas experiências chegaram à indústria;

b) Industrialização: foi o principal fator influenciador para o crescimento populacional das cidades, gerando um esvaziamento do campo para a cidade, uma vez que as pessoas buscavam conforto e oportunidade de trabalho;

c) Avanços na área médica: ampliaram-se hospitais infantis e maternidades, assim como ocorreu a implantação de políticas sanitárias e a descoberta da vacina contra varíola, provocando a queda da mortalidade, principalmente nos países mais ricos;

d) Migrações ultramarinas: entre os anos de 1815 e 1915, aproximadamente 35 milhões de pessoas deixaram a Europa para tentar a vida além-mar;

e) Formação do mercado: o crescimento populacional e urbano aliados ao aumento do poder aquisitivo dos trabalhadores permitiram que indústrias de bens de consumo ampliassem sua produção.

Ocorre que o grande desenvolvimento das indústrias e o aumento da competitividade gerou a redução dos lucros para os detentores do poder econômico, que levados pela ambição e desejosos de aumentar a mais-valia, passaram a adotar várias estratégias para aumento dos lucros, as quais provocaram profundas consequências e alterações sociais.

Dentre as estratégias mais utilizadas pelos detentores do poder econômico, Joselita Matos Damasceno (2014), destaca:

a) substituição da mão de obra masculina pela feminina e infantil, utilizando-se crianças com idades inferiores a oito anos, a troco, muitas vezes, de alojamento e comida;

b) as máquinas passaram a ser utilizadas amplamente, ocasionando um gradativo aperfeiçoamento técnico e a exclusão do mercado de trabalho dos inaptos;

c) com a finalidade de aumentar a produtividade, pagava-se tão pouco ao operário que o mesmo via-se obrigado a trabalhar durante toda a semana para obter uma renda mínima para a sobrevivência, em condições precárias de trabalho, com jornadas médias de 14 horas por dia e que, dependendo da época do ano, poderiam se estender até 19 horas. E sem quaisquer direitos trabalhistas;

d) criaram-se as workhouses, que eram "casas de trabalho". Trata-se de um local público para onde eram encaminhados os desempregados que ficavam confinados à espera de trabalho. Essas pessoas eram disponibilizadas para os 
industriais como uma mão de obra baratíssima.

No final do Século XIX, estudiosos como M. Defleur e Sandra Ball-Rokeach definiram a sociedade de massas como:

O relacionamento existente entre indivíduos e a ordem social que os rodeia, na qual: 1) os indivíduos são considerados numa situação de isolamento psicológico uns dos outros; 2) diz-se predominar a impessoalidade em suas interações com outros; 3 ) são considerados isentos das exigências de obrigações sociais informais forçosas (DEFLEUR apud MATOS, 2014).

Hannah Arendt aborda a respeito da alienação do Homem moderno com relação ao mundo e situação do homem componente da grande massa, expropriada da proteção da família e de seus bens, como o fazedor, fabricante:

A grandeza da descoberta de Max Weber quanto às origens do capitalismo reside precisamente em sua demonstração de que é possível haver enorme atividade, estritamente mundana, sem que haja grande preocupação ou satisfação com o mundo, atividade cuja motivação mais profunda é, ao contrário, a preocupação e o cuidado com o ego. $\mathrm{O}$ que distingue a era moderna é a alienação em relação ao mundo e não, como pensava Marx, a alienação com relação ao ego (ARENDT, 2007, p. 266).

$[\ldots]$

O fato de que a moderna alienação do mundo foi suficientemente radical para estender-se até mesmo à mais mundana das atividades humanas, ao trabalho e a reificação, à fabricação de coisas e a construção do mundo, distingue as atitudes e avaliações modernas ainda mais nitidamente daquelas da tradição que a mera inversão de posições entre a contemplação e a ação, entre a atividade de pensar e a atividade de agir, parece indicar. O rompimento com a contemplação foi consumado não com a promoção do homem fabricante à posição antes ocupada pelo homem contemplativo, mas com a introdução do conceito de processo na atividade da fabricação (Id. Ibid, p. 314).

Assim, grande parte da população que migrou para as cidades passou a trabalhar nas indústrias e a viver em condições precárias, trabalhando muito, ganhando o mínimo para sua subsistência e sonhando em consumir o produto que produzia, nada tendo de direitos sociais ${ }^{11}$, apenas a liberdade, direito fundamen-

\footnotetext{
${ }^{11}$ Atualmente, no Brasil, acerca dos direitos sociais, consultem-se os arts. $6^{\circ}$ a 11 , da Constituição da República Federativa do Brasil de 1988, em especial o art. $6^{\circ}$, com a redação dada pela Emenda Constitucional n. 64, de 2010: "Art. $6^{\circ}$. São direitos sociais a educação, a saúde, a alimentação, o trabalho, a moradia, o lazer, a segurança, a previdência social, a proteção à maternidade e à infância,
} 
tal nos Estados Liberais, e aqui, a liberdade para fabricar e aos grandes detentores do capital a liberdade de acumular riquezas e explorar o pobre.

Celso Lafer, ao estudar a obra A condição Humana, de Hannah Arendt, extrai preciosos esclarecimentos sobre as implicações políticas do mundo moderno, as quais levam a pessoa a uma alienação e fragilidade política:

Pois bem: o que é que Hannah Arendt estava tentando compreender em The Human Condition, dos problemas por ela suscitados em The Origins of Totalitarianism? As origens do isolamento e do desenraizamento, sem os quais não se instaura o totalitarismo, entendido como uma nova forma de governo e dominação, baseado na organização burocrática de massas, no terror e na ideologia.

O isolamento destrói a capacidade política, a faculdade de agir. É aquele $<<$ impasse no qual os homens se veem quando a esfera política de suas vidas, onde agem em conjunto na realização de um interesse comum é destruído.>> O isolamento, que é a base de toda tirania, não atinge, no entanto, a esfera privada. $\mathrm{O}$ inédito, no totalitarismo, dada a ubiquidade de seu processo de dominação, é que exige também o desenraizamento, que desagrega a vida privada e destrói as ramificações sociais. $<<$ Não ter raízes significa não ter no mundo um lugar reconhecido e garantido pelos outros; ser suplérfluo significa não pertencer ao mundo de forma alguma. Esta conjugação de isolamento, destruidor das capacidades políticas, e desenraizamento, destruidor das capacidades de relacionamento social, que permite a dominação totalitária, se produz quando: $<<\mathrm{O}$ homem isolado, que perdeu seu lugar no terreno político da ação, é também abandonado pelo mundo das coisas, quando já não é reconhecido como homo faber, mas tratado como animal laborans, cujo necessário $<<$ metabolismo com a natureza $>>$ não é do interesse de ninguém (LAFER, 2007, p. 347).

A partir da década de 1990, as novas tecnologias de comunicação transformaram a forma de comunicação da sociedade de massas, principalmente, pela propagação da internet para a população em geral, deixando de ser instrumento exclusivo do exército americano. Joselita Damasceno Matos (2014) comenta que a comunicação segmentada da sociedade de rede tem a particularidade de atingir um número menor de pessoas, se comparado aos meios de comunicação da sociedade de massa, contudo, atinge grupos de pessoas mais específicos. A internet estabelece a conectividade dos indivíduos, sendo um meio que, ao mesmo tempo, propõe o distanciamento físico, mas, também, a proximidade subjetiva e a mobilidade das pessoas.

Segundo Pierre Lévy, citado por Joselita Damasceno Matos, a "raça

a assistência aos desamparados, na forma desta Constituição". 
humana está se tornando um superorganismo a construir sua unidade através do ciberespaço" (LÉVY, 2000, p. 59). Ainda, segundo o filósofo, "o ciberespaço que é o espaço de comunicação aberto pela interconexão global de computadores - ocasiona uma nova configuração de larga escala de comunicação 'muitos para muitos" (Id. Ibid.)

Nessa sociedade, o indivíduo não precisa locomover-se para manter contato com o mundo, tornando o contato presencial cada vez mais raro. É por intermédio da Rede que o indivíduo se movimenta, busca e mantém relacionamentos, uma vez que procura por um ambiente que lhe seja interessante; ali, troca informações, conhecimentos e mantém uma base de uma sociedade segmentada. Observa-se, contudo, que o ser humano inserido no seu nicho, seja um blog, rede social - Orkut, Facebook, MySpace, Twitter - continuará inserido na massa, pois todos esses nichos formam a sociedade (MATOS, 2014).

Desta forma, não há tanta necessidade de contato físico e muito menos com a realidade, fazendo com que a pessoa vá perdendo a noção do tempo real e se torne desejoso de consumir tudo o que puder, no menor tempo possível; é um mundo onde tudo é descartável: até mesmo o ser humano. Nesta sociedade, pode-se dizer que a informação chega ao indivíduo em tempo real e atinge um número imenso de pessoas, as quais, logo passam a interagir, dando suas opiniões e contribuições - positivas ou não - para o desenvolvimento pacífico das relações sociais.

Cumpre ressaltar que os valores se inverteram a tal ponto que se tornou necessário conter a ação humana contra a autodestruição, e, neste aspecto, o Direito tem papel fundamental, agindo conjuntamente com a Filosofia, Sociologia, Biologia e outras áreas que estudam o ser humano, seu comportamento e o ambiente em que vive.

Assis, Kumpel e Serafim ressaltam a importância da Sociologia para o Direito, especialmente quanto a estrutura social, a cultura e as instituições sociais, e destacam o entendimento de Niklas Luhmann, a saber:

Para Niklas Luhmann (1985), o Direito (normas) funciona como um mecanismo que neutraliza a contingência das ações individuais, permitindo que cada ser humano possa esperar, com um mínimo de garantia, o comportamento do outro e vice-versa. Para superar as contingências que afetam as expectativas das partes, são estabelecidas normas que darão às partes as garantias requeridas. As normas, entretanto, só garantem as expectativas, não o comportamento. (...) O Direito, na medida em que garante as expectativas sociais contra a contingência a que estão sujeitas, aparece como uma estrutura do sistema social que confere congruência à generalização das expectativas comportamentais (ASSIS, 2012, p. 365). 
Assim, a Sociologia tem contribuído para a melhoria do sistema jurídico, indicando as áreas de conflito de interesses e as necessidades de mudança social e estratificação social, pois quando a padronização das condutas ou o Direito são usados como instrumentos de gestão governamental, evitam-se relações conflituosas em larga escala (Id. Ibid. p. 367).

\section{O PERSONALISMO ÉTICO}

Muitos filósofos e pensadores lutaram contra a realidade cultural, moral e social que vinha sendo instaurada pela sociedade de massa e, logo após a crise de 1929, iniciaram-se movimentos em oposição ao absolutismo, a objetivação do ser humano, a desigualdade social e o abuso de poder.

Além de pensadores como Hannah Arendt, já citada, o movimento filosófico do personalismo teve como principal meio de difusão a Revista Sprit, fundada por Emmanuel Monier em 1932, na qual os filósofos mais representativos na França, como G. Izard, P; Ricoeur, N. Berdjaev, J. Maritain, E. Mounier, M. Nedoncelle entre outros, publicavam suas teses. O fundamento do personalismo estava pautado na ideia de pessoa, considerada em sua não-objetivação, inviolabilidade, criatividade, liberdade e responsabilidade - era a visão de uma pessoa encarnada em um corpo, situada na história e constitutivamente comunitária (REALE, 2005, p. 399).

Emmanuel Mounier nasceu em 1905, em Grenoble, e faleceu em 1950, em Paris, após um infarto. Para o filósofo, o fim da crise de 1929 retratou não somente a crise econômica, mas, também, moral que vivia a sociedade, gerando inquietações e angústias a ponto de levar muitos indivíduos a cometerem suicídio. Para Emmanuel Mounier, a pessoa não pode ser retratada em sua inteireza, pois pessoa não coincide com personalidade e, para que seja completa, feliz, deveria fazer pelo menos três exercícios essenciais durante a sua vida: (a) buscar a própria vocação, (b) empenhar-se em uma obra, como sinal da própria encarnação e (c) renunciar a si próprio em favor dos outros. Prossegue defendendo um novo modelo de sociedade onde a pessoa assume responsabilidade por sua vida e tem o dever dos outros. Aqui, o Estado existe para a pessoa e não a pessoa para o Estado, devendo ser formado por poderes divididos e contrapostos com a obrigação de proteger a pessoa contra os abusos do próprio poder (Id. Ibid.).

Outro filósofo de grande destaque no personalismo ético é Jacques Maritain, que inclusive discutiu a finalidade do direito nesta nova sociedade, por meio da Teoria do Humanismo Integral (QUEIROZ, 2014).

O filósofo e letrado, Jackes Maritain, nasceu em Paris na data de 18.11.1882 e faleceu em Toulouse em 28.04.1973; casou-se com Raíssa, judia que se converteu ao catolicismo juntamente com o marido. Foi professor nas 
Universidades de Toronto (Canadá), Columbia, Princeton e Chicago e embaixador da França junto ao Vaticano e importante inspirador e um dos redatores da "Declaração Universal de Direitos Humanos" (1948), da ONU (INSTITUTO JACKES MARITAIN DO BRASIL, 2014).

Jackes Maritain considerava os valores cristãos de igualdade, fraternidade e liberdade como fundamentos para a democracia, os direitos humanos, a luta pela paz universal e pela promoção do bem comum e da dignidade da pessoa humana. É considerado o expoente máximo do neotomismo ${ }^{12}$ no Século XX, trazendo reflexões a respeito da situação da sociedade moderna, sua cultura, seus ideais, sua condição moral, política e religiosa. Como fruto dessas reflexões, nasceu a sua célebre teoria do humanismo integral, que alcançou ressonância máxima no campo da filosofia político-social (QUEIROZ, 2014).

O humanismo integral está fundamentado sobre quatro pilares fundamentais, quais sejam: (a) homem como pessoa, (b) lei natural, (c) direitos humanos e (d) bem comum. Como aspecto principal de sua teoria, Jackes Maritain considera que o ser humano é concebido com uma dignidade humana, ou seja, é uma pessoa, por ser dotado de racionalidade e vontade, bem como de individualidade, isto é, forma um todo completo em si, uma vez que possui valores humanos e um espírito digno de respeito e liberdade (QUEIROZ, 2014).

Jacques Maritain era contrário aos poderes absolutos e supremos, defendendo que todos os poderes devem prestar contas, assim como existe uma lei natural que deve ser respeitada por todos, em especial o direito do homem à existência, à liberdade pessoal e à obtenção da perfeição da vida moral (REALE; ANTISERI, 2005, p. 393).

Os filósofos do personalismo ético, assim como outros que defenderam as ideias de concretização da liberdade, igualdade, dignidade da pessoa humana, de respeito à pessoa acima do Estado, democracia, divulgados em contraposição a crise moral e econômica da época, influenciaram o mundo para gerar as mudanças sociais e políticas do período Pós-Segunda Guerra Mundial.

\section{OS NOVOS DIREITOS E A NECESSIDADE DE UM NOVO MODELO CONSTITUCIONAL}

Em um primeiro momento, o constitucionalismo foi compreendido como uma técnica jurídica de proteção das liberdades, reconhecida a partir do final do Século XVIII, a qual, em especial, tem como marco a Revolução Francesa ocorrida em 1789.

Segundo, José Joaquim Gomes Canotilho, citado por Zulmar Fachin (2013, p. 227), o constitucionalismo antigo é conceituado como: "o conjunto

\footnotetext{
${ }^{12}$ Ressurgimento da filosofia de Tomas de Aquino.
} 
de princípios escritos ou consuetudinários alicerçadores da existência de direitos estamentais perante o monarca e simultaneamente limitadores de seu poder. Inicia-se no final da Idade Média e vai até o século XVIII".

A cultura da sociedade de massa e a inversão axiológica sobre a pessoa humana, os horrores da Segunda Guerra Mundial e do Nazifascismo, deixaram claro ao mundo a necessidade de se reconhecer na pessoa um valor maior e antecedente a lei, um valor que lhe fosse inerente, a fim de que seus atributos estivessem protegidos contra abusos do Estado ou de terceiros.

Maria Paula Dallari Bucci explica que:

No século XIX, ao mesmo tempo que as lutas pela ampliação do sufrágio e implantação do regime democrático levavam essas questões ao centro das ideias políticas, estava em curso a mais formidável transformação social da história, com os frutos da revolução industrial e a formação do movimento socialista. A consolidação dos Estados nacionais, nesse período, resultou da interpenetração das dimensões jurídica e política com questões próprias da atividade econômica. A marca do século XX foi a explicitação do poder econômico - em movimentos de ação e reação com as resistências de inspiração socialista - ao mesmo tempo como parceiro e concorrente do Estado.[...] O Estado segundo Max Weber, detém não apenas o monopólio do exercício legítimo da violência, mas também os meios de gestão postos à disposição pela sociedade, os recursos financeiros, oriundos da arrecadação tributária e do crédito público e as estruturas permanentes de atuação, os organismos e a burocracia públicos. Além disso, passou a deter poderes sobre comportamentos privados, diretamente ou por meio de incentivos e mecanismos de indução. À medida que a sociedade se tornava mais complexa, também o Estado necessitou ampliar e diversificar seus modos de atuação. Essa evolução, no sentido de abranger um leque mais amplo de responsabilidades e combinando modos de atuação diversos, como a participação na vida econômica ou a sua regulação, gerou novos problemas e desafios para o direito (BUCCI, 2013, p. 90).

Assim, após o surgimento do proletariado, a sociedade passou a clamar por inclusão na participação das riquezas, contexto no qual era exigido do Estado, não apenas uma abstenção à violação de direitos individuais, mas uma previsão e concretização dos direitos fundamentais. As primeiras constituições a preverem direitos sociais foram a mexicana, em 1917, e a alemã de 1919, embriões do Estado Social de Direito ou Estado do Bem Estar (Welfare State).

Como explica Zulmar Fachin, os direitos passaram a ser reivindicados no decurso da história, sendo divididos pela maioria dos doutrinadores em di- 
mensões, de acordo com as conquistas de cada tempo, não deixando de existir o direito já conquistado quando surge um novo direito. Confirmando este entendimento, o referido autor cita Ingo Sarlet, para quem "os direitos fundamentais são, acima de tudo, fruto de reivindicações concretas, gerada por situações de injustiça e/ou agressão a bens fundamentais e elementares do ser humano" (FACHIN, 2013, p. 227).

A decadência axiológica do ser humano trouxe consigo a necessidade de se elevarem determinados direitos à categoria constitucional, conhecidos como de terceira, quarta e quinta dimensões, tendo em vista os avanços da ciência, tecnologia e a complexidade das relações sociais. Segundo Zulmar Fachin (2013, p. 222-229), os direitos fundamentais estão assim divididos:

a) Direitos de primeira dimensão: os quais correspondem aos direitos civis e políticos, essencialmente ligados às liberdades individuais, sendo reivindicados a partir de 1215, com a Carta Magna assinada pelo Rei João Sem-Terra, na Inglaterra;

b) Direitos de segunda dimensão: abrangem os direitos sociais, culturais e econômicos, assentados sobre a igualdade;

c) Direitos de terceira dimensão: consubstanciados nos direitos metaindividuais, coletivos e difusos, estão vinculados à solidariedade e podem refletir-se na paz, desenvolvimento, comunicação, ambiente ecologicamente equilibrado e patrimônio comum da humanidade;

d) Direitos de quarta dimensão: estão elencados o direito à informação verdadeira, à democracia e o pluralismo;

e) Direitos de quinta dimensão: decorrem da incerteza e insegurança gerada em todo o mundo, tendo em vista os extermínios em massa, de vidas humanas, ocorridos no Século XX, como genocídios, guerras mundiais, bombas atômicas, atos terroristas, apartheid, limpezas étnicas; sendo assim, a paz seria $\mathrm{o}$ precioso bem a ser resguardado nesta dimensão;

f) Direitos de sexta dimensão: em virtude da escassez e por ser um bem essencial à vida, é necessário elevar-se o direito à água potável.

Note-se que o Constitucionalismo Antigo, que previa sobre a organização do poder estatal e impunha um Estado de Direito, tornou-se impotente frente às demandas da sociedade e o surgimento de novos direitos. A sua tutela era limitada e não realizava a desejada transformação social e redução das desigualdades; almejava-se uma proteção mais ampla, efetiva e democrática, que melhor integralizasse as massas, que é o que se busca com a formação do Estado Democrático de Direito e o Constitucionalismo Moderno.

A partir do Século XVIII nasce o Constitucionalismo Moderno, como um movimento político, social e cultural questionador do domínio político tradicional, eivado de sentimento nacional, limitador do poder do Estado e garantidor 
das liberdades fundamentais da pessoa humana. Encontram representantes nos movimentos inglês, americano e francês (FACHIN, 2013, p. 36-41).

A ideia central da democracia de Lincoln, expressa, em 1863, na frase "governo do povo, pelo povo e para o povo", significa que o povo deve deixar de ser objeto para tornar-se sujeito do governo democrático, refletindo nos conceitos de soberania popular, igualdade e autogoverno, caracterizando-se pelo voto - que define os modos de transmissão do poder dos eleitores aos representantes ${ }^{13}$ - como pressuposto da igualdade jurídica (Id Ibid. p. 87). A democracia consagrou a supremacia do Parlamento e da lei, o funcionamento do Poder Judiciário e os mecanismos de controle do poder pelo poder (Id. Ibid. p. 89).

Assis, Kumpel e Serafim comentam que:

O acesso à justiça é um problema antigo que se acentuou no período de pós-guerra, quando a consagração constitucional de novos direitos econômicos e sociais transformou o direito ao acesso efetivo à justiça num direito cuja denegação comprometeria todos os demais, ou seja, sem acesso à justiça os novos direitos sociais e econômicos seriam simplesmente meras declarações políticas, de conteúdo e função mistificadores (ASSIS, 2012, p. 453).

O Constitucionalismo Moderno necessita de um sistema jurídico efetivo e eficaz, e, para tanto, foram disseminadas formas de controle concentrado de constitucionalidade, as quais desencadearam uma ampliação da função judicial, com a criação e funcionamento dos Tribunais e Conselhos Constitucionais; assim como as Cortes de Direitos Humanos e, consequentemente, modificação do papel da Constituição, que assumiu definitivamente o sentido de norma jurídica - não mais mero pacto político - o que repercute sobre a aplicação do Direito quando se desce verticalmente pela hierarquia normativa (BUCCI, 2013, p. 95).

Com efeito, os Tribunais e Cortes deveriam ser instrumentos para concretização dos direitos fundamentais, vez que o acesso à justiça passou a ser pautado na dignidade da pessoa humana, pois o Poder Judiciário era, até então, o meio mais eficaz para a pessoa alcançar o direito ou fazer cessar a violação ou ameaça a direito seu. Atualmente, os direitos fundamentais também são concretizados por meio de políticas públicas e, ainda, extrajudicialmente, por métodos alternativos, dentre eles, destacam-se os autocompositivos, que buscam trazer uma solução justa aos conflitos de interesses, sejam individuais ou sociais; portanto, o Poder Judiciário não deve mais ser visto como o único meio para concretização de direitos e, sobretudos, de direitos fundamentais.

${ }^{13}$ É, aliás, o que consta do parágrafo único, do art. $1^{\circ}$, da Constituição da República Federativa do Brasil de 1988, in verbis: “[...] Parágrafo único. Todo o poder emana do povo, que o exerce por meio de representantes eleitos ou diretamente, nos termos desta Constituição". 


\section{O MITO DO JUDICIÁRIO E O EFETIVO ACESSO À JUSTIÇA}

Todas estas transformações, que culminaram no surgimento dos Estados Modernos, exigiram, a princípio, um Estado centralizado e forte, principalmente após o surgimento do capitalismo mercantil e a superação do modo de produção feudal durante os Séculos XIV, XV e XVI, trazendo valor à ação exclusiva do Estado - na figura do Poder Judiciário - na solução dos conflitos de interesses. Com a democratização, o Estado não poderia mais se escusar de cumprir tal tarefa de forma igualitária.

Nesse novo contexto mundial, a dignidade da pessoa humana adquire contornos de prestação positiva por intermédio do dever de tutela, jurídica e jurisdicional, de direitos pelo Estado. O texto constitucional brasileiro enumera, como um dos fundamentos do presente Estado Democrático de Direito, a dignidade da pessoa humana, conforme previsto no art. $1^{\circ}$, inc. III da CRF $/ 88$.

Dada sua vital importância, este princípio deve ser interpretado, no ordenamento jurídico pátrio, da maneira mais ampla possível, devendo o Estado brasileiro prover de todos os meios possíveis para assegurar sua efetivação, não apenas por intermédio de garantias constitucionais de caráter individual, mas, também, pela defesa de interesses coletivos, difusos e metaindividuais.

Nesse contexto, ou seja, de uma interpretação mais ampla possível, os princípios, como espécies de normas jurídicas, estão no plano genérico e do abstrato, enquanto as regras atuam no plano da realidade. Mas isso não significa que o princípio não venha a ter incidência no caso concreto. Os princípios integram o sistema jurídico e, desse modo, quando da aplicação do Direito, numa interpretação do sistema, deve o intérprete levá-los em consideração. Assim, a interpretação de um texto legal, nos dias atuais, não pode mais ser feita com base exclusivamente nesse texto, utilizando-se dos métodos mais antigos (histórico, gramatical, teleológico, lógico-sistemático, etc.). A interpretação deve ter tal aextensão, a fim de abarcar o sistema jurídico em sua estrutura global. Daí a relevância de enfocar o texto da Constituição como ponto de partida de toda e qualquer interpretação. É partindo da Constituição e descendo às demais regras jurídicas, perpassando todo o ordenamento jurídico, que o intérprete fará uma interpretação mais adequada e correta. A interpretação, nesses moldes, é de suma importância, mormente quando se aborda o princípio da dignidade da pessoa humana. Na lição de Luiz Antônio Rizzatto Nunes, a interpretação “(...) 'conforme à Constituição’ busca apontar as opções valorativas básicas do Texto Máximo, os princípios tornam-se importantíssimos no trabalho do intérprete, não só porque são, de fato, superiores às normas, ainda que constitucionais, mas especialmente porque, ao contrário das normas, que ao se chocarem geram antinomias, eles são compatibilizáveis. É claro que, mesmo assim, essa compatibilização deverá 
pôr em relevo aquele princípio mais influente no contexto analisado - como, da mesma forma, deve-se dar sempre maior importância aos princípios mais fundamentais, como, por exemplo, o da dignidade da pessoa humana" (NUNES, 2002, p. 33$)^{14}$.

Assim, a ideia de que a tutela do Estado, por meio da jurisdição, seria a melhor solução para os conflitos de interesses, tendo em vista a garantia de imparcialidade, do contraditório, da ampla defesa e a responsabilidade de dar efetivo acesso a todos, como preceitua o inciso XXXV, do art. $5^{\circ} \mathrm{da} \mathrm{CF}$, foi sendo propagado, desde a consolidação do Estado democrático de direito (CINTRA, 2007, p. 40).

Nas palavras de Petronio Calmon, o sentimento de exaltação da justiça estatal é fruto do mito da justiça, ou seja, a crença de que o processo garantirá a independência e imparcialidade do juiz, tendo em vista a motivação das decisões, da iniciativa por um sujeito diverso do julgador, da paridade de armas, contraditório, ampla defesa e definitividade de suas decisões, em que, para as partes, somente um juiz pode dar uma decisão correta e justa (CALMON, 2013, p. 34).

A orientação teórica da Escola do Direito Livre, com Ehrlich, Kantorowich, e a jurisprudência sociológica, de Roscoe Pound, já no início do Século $\mathrm{XX}$, criaram as pré-condições teóricas da transição para uma nova visão sociológica focada nas dimensões processuais, institucionais e organizacionais do direito (ASSIS, 2012, p. 450).

A cultura litigiosa, desencadeada pela crença de que o Poder Judiciário, até então, era a forma mais justa de se solucionar os conflitos de interesses, instaurou-se em todo o mundo ocidental, criando uma crise generalizada do Poder Judiciário e obstáculos infindáveis ao efetivo acesso à justiça. Segundo Ada Pelegrini Grinover (1988, p. 278), os principais fatores para essa crise são:

a sobrecarga dos tribunais, a morosidade dos processos, seu custo, a burocratização da Justiça, certa complicação procedimental, a menta-

\footnotetext{
${ }^{14}$ Consulte-se, ainda, Flademir Jerônimo Belinati Martins: "14. Os princípios fundamentais, ao menos do ponto de vista material, são dotados de superioridade em relação aos demais princípios constitucionais, sendo aplicáveis a todo o sistema jurídico constitucional. Em outros termos, diríamos que os princípios fundamentais conformam, orientam e limitam criticamente a interpretação de todo o ordenamento. Assim, concluímos que o princípio fundamental da dignidade da pessoa humana, enquanto expressão positiva do valor fonte do ordenamento constitucional brasileiro, acaba por funcionar como um operador deôntico especial, pois, mesmo quando não esteja diretamente envolvido na solução jurídica do caso concreto, o valor que ele traduz será chamado a conformar, orientar e limitar a opção realizada. Dessa forma, ainda que o caso concreto seja posto em termos em que não se exija a imediata incidência do princípio da dignidade da pessoa humana, não se deve olvidar que, na qualidade de operador deôntico especial, a dignidade da pessoa humana sempre deverá conformar, orientar e limitar criticamente a opção realizada". [MARTINS, Flademir Jerônimo Belinati. In Dignidade da pessoa humana: princípio constitucional fundamental. Curitiba: Juruá, 2003, p. 126-127].
} 
lidade do juiz que deixa de fazer uso dos poderes que os códigos the atribuem, a falta de informação e de orientação para os detentores dos interesses em conflito e as deficiências do patrocínio gratuito.

Atualmente, verifica-se que as barreiras para o acesso à justiça são de ordem econômica, cultural e social. Segundo Ada Pellegrini Grinover, citada por Petronio Calmon, o processo judicial tradicional não está adequado para a solução dos conflitos de interesses emergentes em uma sociedade de massa, em que despontam interesses metaindividuais e interesses economicamente menores (CALMON, 2013, p. 39).

As soluções para a crise do Poder Judiciário, segundo sociólogos e processualistas, estão centradas em dois aspectos: o jurisdicional e o extrajudicial. Assim, a vertente jurisdicional defende a descomplicação do próprio processo, tornando-o mais ágil, mais rápido, mais direto, mais acessível. Com relação a essa característica almejada, Ada Pelegrini Grinover trata como deformalização do processo. E, a vertente extrajudicial, por meio da qual se busca a desformalização das controvérsias, pelos equivalentes jurisdicionais, como vias alternativas ao processo, encaixando-se aqui a conciliação e a mediação - métodos autocompositivos -, e a arbitragem - método heterocompositivo (SENA, 2014).

Os movimentos feitos, em todo o mundo, para reformas e implantação de mecanismos com objetivo de dar efetivo acesso à justiça, foram chamados por Mauro Capelletti e Bryan Garth de "ondas". A primeira "onda" ampliou o acesso ao Poder Judiciário para os menos abastados, tanto com relação a custas e despesas processuais quanto em relação aos honorários advocatícios. No Brasil, é de se ressaltar o texto constitucional quando, no Título que trata Dos direitos e garantias fundamentais, direitos individuais e coletivos, prevê no inc. LXXIV, do art. $5^{015}$, a assistência jurídica, bem como a Defensoria Pública, como função essencial à justiça, prevista no art. $134^{16}$, do mesmo texto legal.

Cumpre ressaltar que a abertura econômica do Poder Judiciário desencadeou uma sobrecarga de processos, tendo em vista a quantidade de ações e processos em trâmite e a impossibilidade de atender a demanda existente, tanto pela complexidade dos conflitos de interesses quanto pela sua quantidade, tornando o

\footnotetext{
15“Art. $5^{\circ}$. Todos são iguais perante a lei, sem distinção de qualquer natureza, garantindo-se aos brasileiros e aos estrangeiros residentes no País a inviolabilidade do direito à vida, à liberdade, à igualdade, à segurança e à propriedade, nos termos seguintes: [...] LXXIV - o Estado prestará assistência jurídica integral e gratuita aos que comprovarem insuficiência de recursos; [...]". 16“Art. 134. A Defensoria Pública é instituição permanente, essencial à função jurisdicional do Estado, incumbindo-lhe, como expressão e instrumento do regime democrático, fundamentalmente, a orientação jurídica, a promoção dos direitos humanos e a defesa, em todos os graus, judicial e extrajudicial, dos direitos individuais e coletivos, de forma integral e gratuita, aos necessitados, na forma do inciso LXXIV do art. $5^{\circ}$ desta Constituição Federal".
} 
processo lento, moroso e custoso, ou seja, algumas das soluções, inevitavelmente, trouxeram novos problemas para o serviço do Poder Judiciário.

Embora sejam inúmeras as causas originadoras da crise do Poder Judiciário, os doutrinadores, estrangeiros e nacionais, concordam que o excessivo número de processos que chegam ao Poder Judiciário anualmente - demonstrando uma cultura litigiosa - é uma das principais agravantes para o congestionamento existente e, consequentemente, para a restrição ao acesso à Justiça.

Pode-se afirmar que foi a partir da década de 1960 que se intensificaram os estudos sobre meios extrajudiciais de solução de conflitos de interesses, como a conciliação e a mediação, a partir de questionamentos levantados por Frank Sander, discípulo de Roscoe Pound, na Pound Conference, realizada em Mineápolis no ano de 1976, quando utilizou pela primeira vez o termo ADR Alternative Dispute Resolution (SANDER, 1976, p. 111).

Dessa forma, a Antropologia Social também trouxe várias contribuições para esclarecimentos sobre a administração da justiça por meio de outros mecanismos de resolução, conforme explicam Assis, Kumpel e Serafim:

Os antropólogos, ao investigar as sociedades simples, mostraram formas de direito e padrões de vida jurídica totalmente diferentes dos existentes nas sociedades complexas, tais como: a) direitos com baixo grau de abstração e apenas discerníveis na solução concreta de litígios; b) direitos com pouca especialização em relação às restantes atividades sociais; c) mecanismos de resolução de litígios caracterizados pela informalidade, rapidez, participação da comunidade, conciliação ou mediação entre as partes através de discurso jurídico retórico e persuasivo, assente na linguagem comum; d) existência, numa mesma sociedade, de uma pluralidade de direitos convivendo e interagindo de diferentes formas (ASSIS; KUMPEL; SERAFIM 2012, p. 459).

A desenfreada busca pelo acesso à justiça por meio da prestação jurisdicional e a sua crise, desencadeou, assim, a necessidade de se encontrar outros caminhos, inclusive por métodos autocompositivos, que assegurem uma resposta realmente justa, pois o conceito de justiça não pode comportar uma decisão tardia e sem efeito prático, ou até insatisfatória às partes. Aliás, já foi dito que Justiça tardia equivale à injustiça; Justiça tardia é Justiça desmoralizada.

A respeito, Petronio Calmon (2013, p. 32) explica que, em verdade, o Poder Judiciário não evoluiu simplesmente da autotutela, como defendem muitos processualistas, mas que a autotutela e a autocomposição sempre coexistiram como meio de solução de conflitos, antes mesmo da criação do Poder Judiciário. Isso tanto é verdadeiro, que na Bíblia Sagrada, em Mateus, Capítulo 5, versículos 
21 a 25 está escrito:

21 "Vocês ouviram o que foi dito aos seus antepassados: 'Não matarás', e 'quem matar estará sujeito a julgamento'.

22 Mas eu digo a vocês que qualquer que se irar contra seu irmão estará sujeito a julgamento. Também, qualquer que disser a seu irmão: 'Racá', será levado ao tribunal. E qualquer que disser: 'Louco!', corre o risco de ir para o fogo do inferno.

23 "Portanto, se você estiver apresentando sua oferta diante do altar e ali se lembrar de que seu irmão tem algo contra você,

24 deixe sua oferta ali, diante do altar, e vá primeiro reconciliar-se com seu irmão; depois volte e apresente sua oferta.

25 "Entre em acordo depressa com seu adversário que pretende levá-lo ao tribunal. Faça isso enquanto ainda estiver com ele a caminho, pois, caso contrário, ele poderá entregá-lo ao juiz, e o juiz ao guarda, e você poderá ser jogado na prisão.

Também o Pensador Confúcio afirmava: "Aja antes de falar e, portanto, fale de acordo com os seus atos".

$\mathrm{Na}$ atualidade, já se comprovou que a decisão judicial, tanto pelo procedimento prolongado e burocrático, moroso, custoso, como pela expectativa das partes, já não traz uma satisfação plena às mesmas - por vezes, nem mesmo à parte vencedora. Inúmeros estudos indicam que a satisfação dos usuários do sistema judicial está fortemente relacionada à percepção de que o procedimento foi justo e na possibilidade das partes envolverem-se diretamente na escolha dos procedimentos usados para solucionar o conflito (AZEVEDO, 2013, p. 23).

Enfim, o sentimento de justiça deixou, há muito, de ser suprido pela prestação jurisdicional, a cargo do Estado-juiz, desmistificando o Poder Judiciário como a única forma garantidora de uma decisão imparcial e justa, fundamentada no princípio da dignidade da pessoa humana; ao mesmo tempo, a cultura litigiosa instaurada por décadas, tornou os indivíduos impotentes para resolverem suas próprias questões por meio da autocomposição. Portanto, conclui-se que a jurisdição não é, em tese, "melhor" nem "pior" que outros métodos de solução de conflitos de interesses; assim, não se deve falar em um mecanismo mais eficiente, mas naquele mais funcional para dada situação concreta, ou seja, a funcionalidade do instrumental e da metodologia de gestão de conflitos de interesses, disputas e problemas, implica adequação da via possível e assimilável pelo contexto conflitivo (Id Ibid, p. 28). Destarte, objetiva-se elencar os principais métodos de solução de conflitos de interesses, sob a ótica de métodos auxiliares e eficazes para a mudança de mentalidade da sociedade, do jurisdicionado, com a obtenção do escopo magno da jurisdição que é a pacificação social, e, consequentemente, a diminuição do número de processos e o afastamento da morosidade do Poder 
Judiciário.

Deve-se observar que no Brasil, desde o Império, já se reconhecia, ainda que timidamente, a importância da conciliação, como método autocompositivo, o qual tinha previsão nas Ordenações Filipinas, Livro III, Título XX, $\S 1^{\circ}$, a saber: "No comêço da demanda dirá o juiz a ambas as partes, que antes que façam despesas, e se sigam entre elas o ódio e dissensões, se devem concordar, e não gastarem suas fazendas por seguirem suas vontades, porque o convencimento da causa sempre é duvidoso" (RUIZ, 2003, p. 193).

A conciliação sofreu várias mudanças no decorrer da história brasileira, chegando a ser prevista como um requisito pré-processual a ser tentada pelas partes, diante dos juízes de paz, sendo conhecida como conciliação prévia. Contudo, retornou ao seu status quo de facultatividade com o Decreto 359, 26 de abril de 1890, o qual revogou as leis que exigiam a tentativa de conciliação prévia (Id. Ibid. p. 193).

Atualmente, a conciliação está prevista em praticamente todos os ritos procedimentais: amplamente, na esfera cível, trabalhista e juizados especiais cíveis, estaduais e federais, sendo obrigatória, a sua tentativa, no início da demanda ou facultativa no decorrer de todo o processo (art. 125 ${ }^{17}$, inc. IV, do CPC/1973), em qualquer fase processual, inclusive, em segunda instância.

A arbitragem também possui tradição em nosso direito, embora não seja tão utilizada como a conciliação, eis que teve previsão nas Constituições de 1824, 1934 e 1937; as demais, incluindo a Constituição Cidadã de 1988, nada previram a respeito, havendo, todavia, previsão infraconstitucional para utilização da mesma (Id. Ibid. p. 190). Atualmente, a arbitragem está regulamentada pela Lei federal n. 9.307/96 e pode ser utilizada apenas em situações que envolvam direitos patrimoniais disponíveis. Mas, é de se ressaltar que grande parte da doutrina brasileira entende que na Arbitragem, apesar de método alternativo de solução de conflitos de interesses, está presente o exercício da jurisdição (NERY; JUNIOR, 2009, p. 153-155).

Entretanto, nem mesmo a obrigatoriedade da conciliação no processo judicial e a publicação da Lei federal n. 9.307/96 foram suficientes para auxiliar, de forma efetiva, na pacificação social e diminuição do ajuizamento de processos no país. Tal constatação observa-se, primeiramente, pelo desvio das técnicas de conciliação que eram aplicadas por servidores ou estudantes de direito, totalmente despreparados para tanto, bem como, no caso da arbitragem, por tratar de matéria bastante limitada e ser, ainda, de custo elevado para a maioria da população.

Em decorrência da necessidade de outras soluções ou da aplicação efetiva dos métodos autocompositivos, o Conselho Nacional de Justiça (CNJ) apro-

17“"Art. 125. O juiz dirigirá o processo conforme as disposições deste Código, competindo-lhe: [...] IV - tentar, a qualquer tempo, conciliar as partes". 
vou a Resolução sob on. 125/2010, proposta por Kazuo Watanabe, instituindo no Brasil a Política Pública de Tratamento Adequado de Conflitos. A referida Resolução propôs obrigações aos Entes Federados, Órgãos Públicos e Privados, trazendo em seu bojo a obrigatoriedade da criação dos Núcleos Permanentes de Métodos Consensuais de Solução de Conflitos pelos Tribunais Nacionais, conforme previsão do art. $7^{\circ}$ da Resolução n. 125/2010 e a instauração de Centros Judiciários nas comarcas respectivas, a fim de prestar serviços de mediação, conciliação e informação gratuitamente à população.

A novidade da Resolução é a tentativa de implantar a mediação no Brasil, assim como exigir dos mediadores e conciliadores extrajudiciais a capacitação em curso fornecido pelos próprios tribunais e padronizado segundo o Conselho Nacional de Justiça.

Como método autocompositivo, a mediação tem a vantagem de preocupar-se com o empoderamento das partes e a solução do conflito intersubjetivo, ou seja, visa muito mais a pacificação social que qualquer outro método até então utilizado, pois vai além das posições demonstradas pelas partes, alcançando seus reais interesses e necessidades.

São métodos realmente mais baratos que o processo judicial, além de mais céleres e de trazerem maior satisfação às partes envolvidas no conflito de interesses. Contudo, o que se teme é a forma de implantação e aplicação de tais métodos, que venham a ser tratados com o mesmo descaso com que a conciliação judicial tem sido tratada há décadas no país. Tal fato constata-se, facilmente, na observância das pautas de audiências, em que é comum a marcação de prazo de cinco minutos entre uma e outra audiência, para sua realização.

As barreiras para implantação adequada dos métodos autocompositivos pelos CEJUSC's já podem ser vislumbrados por qualquer pessoa, a começar pela falta de investimento em prédios separados do Poder Judiciário, desvinculando a sua imagem da função jurisdicional. Tal fator tem importância quando se analisam os princípios norteadores da mediação, vez que exige um ambiente sigiloso e tranquilo, que não remeta as partes à oposição existente no processo judicial. Em que pese tais verdades, contudo, o foco do presente artigo, não é criticar a forma de implantação destes métodos no país, o que será objeto de outro estudo, mas demonstrar a importância da autocomposição na sociedade de massa e de rede, vez que concedem as pessoas condições de refletir sobre o conflito de interesses e participar na sua resolução, tirando o ser humano da posição de conformismo e alienação de homem massificado e concretizando um dos princípios basilares de todos os demais que lhe são inerentes. 


\section{CONSIDERAÇÕES FINAIS}

A dignidade da pessoa humana, como princípio universal é, atualmente, o fundamento para que o Poder Público preste um serviço jurisdicional eficiente e igualitário. No Estado Democrático de Direito, não se concebe mais a ideia de que a pessoa não tenha o seu direito e garantia fundamental concretizado por obstáculos econômicos, sociais e culturais.

Lamentavelmente, vive-se, ainda, a cultura da objetivação do ser humano, tendo em vista que a cada dia os relacionamentos físicos são menos importantes na sociedade de rede, pois nesta, a pessoa se movimenta e relaciona por intermédio da internet. A pessoa massificada é alienada, manipulada pelos detentores do Poder, e tem o consumo como uma de suas prioridades, até mesmo para ser aceito em seu nicho, fazendo disso o alvo principal da sua vida, onde tudo torna-se objeto de compra - inclusive os atributos da própria personalidade.

Desta forma, para que a pessoa não se autodestrua, é necessário que o sistema jurídico, por meio de pensadores do Direito, filósofos, sociólogos etc, caminhe de forma a conter a objetivação do ser humano, tratando-o como um ser que merece ser respeitado por sua natureza humana e que deve respeitar os demais seres vivos, em especial, o outro ser humano com quem convive.

Nem mesmo o Estado pode violar a dignidade da pessoa humana, mas, ao contrário, deve lutar para que seus direitos e garantias fundamentais sejam protegidos e concretizados, também, por meio do Poder Judiciário, concedendo-lhe acesso efetivo ao processo, bem como a outros meios de solução de conflitos de interesses tão eficazes quanto, ou até mais satisfatórios, que a própria decisão judicial.

O processualista, desde a década de 1970, vem identificando a necessidade de incentivar os meios autocompositivos, já existentes antes da mitificação do Poder Judiciário e do seu aparente monopólio para solução dos conflitos de interesses, derrubada pela crise mundial do mesmo e agora fundamentada no princípio da dignidade da pessoa humana, que reconhece o direito ao acesso efetivo à justiça.

\section{REFERÊNCIAS}

AGÊNCIA CNJ de notícias. País tem quase 90 milhões de processos em tramitação na Justiça. Disponível em: < http://www.cnj.jus.br/noticias/9783pais-tem-quase-90-milhoes-de-processos-em-tramitacao-na-justica $>$. Acesso em: 29 ago. 2013.

ARENDT, H. A condição humana. 10. ed. Rio de Janeiro: Forense 
Universitária, 2007.

ASSIS, A. E. S. et al. Noções gerais de direito e formação humanística. São Paulo: Saraiva. 2012.

AZEVEDO, A. G. (Org.) 2013. Manual de Mediação Judicial. Ministério da Justiça e Programa das Nações Unidas para o Desenvolvimento - PNUD. 2013.

BARBOSA, J. de M.; ABREU, R. R. de. O instituto da mediação (parte II). Revista de arbitragem e mediação. São Paulo: Revista dos Tribunais, 2009. v. 22.

BEDÊ, J.; RUIZ, I. A. Estudos preliminares sobre mediação. Revista Jurídica -Cesumar, v. 8, n. 1, p. 163-177, jan./jun. 2008.

BEZERRA, C. S. Temas atuais de direitos fundamentais. 2. ed. Ilhéus: Editus/UESC, 2007.

CALMON, P. Fundamentos da mediação e da conciliação. 2. ed. Brasília: Gazeta Jurídica, 2013.

CAHALI, F. J. Curso de arbitragem: Resolução CNJ 125/2010: mediação e conciliação. 2. ed. São Paulo: Revista dos Tribunais. 2012.

CAPELLETTI, M. Acesso à justiça. Tradução de Ellen Gracei Northfleet. Porto Alegre: Fabris, 1988.

CINTRA, A. C. de A.; GRINOVER, A. P.; DINAMARCO, C. R. Teoria geral do processo. 23. ed. São Paulo: Malheiros. 2007.

CONSELHO NACIONAL DE JUSTIÇA. RESOLUÇÃO nํำ125, de 29 de novembro de 2010. Dispõe sobre Política Judiciária Nacional de tratamento adequado dos conflitos de interesses no âmbito do Poder Judiciário e dá outras providências. Presidente do Conselho Nacional de Justiça Ministro Cesar Peluso. Disponível em: $<$ http://www.cnj.jus.br/images/stories/docs_cnj/ resolucao/resolucao-n-125-GP.pdf $>$. Acesso em: 01 maio 2013.

CURSINO, R. B. Da mediação como eficiente forma de pacificação social. Brasília: Conteúdo Jurídico. 2012. Disponível em: <http://www. conteudojuridico.com.br/?artigos\&ver=2.40904\&seo=1 > . Acesso em: 06 set. 
2013.

FACHIN, Z. Curso de direito constitucional. 6. ed. Rio de Janeiro: Forense. 2013.

FOLBERG, J; TAYLOR, A. Mediación: resolución de conflictos sin litígio. México: Limusa Noriega, 1997.

INSTITUTO JACKES MARITAIN DO BRASIL. Biografia de Jackes Maritain. Disponível em: $<$ http://site1375985351.hospedagemdesites.ws/site/o-instituto/ quem-somos/ >. Acesso em: 20 ago.14.

QUEIROZ, A. Jacques Maritain e o humanismo integral. Disponível em: $<$ http://culturageralsaibamais.wordpress.com/2011/04/28/jacques-maritain-e-ohumanismo-integral/>. Acesso em: 20 ago. 2014.

MARTINS, F. J. B. In: . Dignidade da pessoa humana: princípio constitucional fundamental. Curitiba: Juruá, 2003.

MATOS, J. D. A sociedade de massa na era da cibercultura: a informação segmentada. Disponível em: < http://jdmatos.wordpress.com/2011/07/17/asociedade-de-massa-na-era-da-cibercultura-a-informacao-segmentada/ $>$. Acesso em: 20 ago. 2014.

NADER, L. Harmonia coercitiva: a econômica política dos modelos jurídicos. Disponível em: $<$ http://www.anpocs.org.br/portal/publicacoes/rbcs_00_26/ rcbs26_02.htm >. Acesso em: 28 ago. 2013.

NERY JUNIOR, N. Princípios do processo na Constituição Federal: processo civil, penal e administrativo. 9. ed. São Paulo: Revista dos Tribunais, 2009.

NUNES, L. A. R. O princípio constitucional da dignidade da pessoa humana: doutrina e jurisprudência. São Paulo: Saraiva, 2002.

REALE, G.; ANTISERI, D. História da filosofia. 6: de Nietzshce à escola de Frankfurt. São Paulo: Paulus, 2005.

RUIZ, I. A. Estudo sobre mediação no direito brasileiro: Natureza juridical e outros aspectos fundamentais. 2003. ...f. Tese (Doutorado) - Pontifícia Universidade Católica de São Paulo, São Paulo, 2003. 
. A Autocomposição nas relações de família. Revista Jurídica

Cesumar, v. 5, n. 1, p. 51-74, 2005.

RUIZ, I. A.; GONÇALVES, H. A. C. Da conciliação: uma forma de efetivar a jurisdição, pela via consensual, por meio de um processo mais justo. Revista Jurídica - Cesumar, v. 11, n. 1, p. 53-80, 2011.

RECHE, M. A. L. R. NUNES, Taís Zanini de Sá Duarte Nunes. Mediação Forense: aspectos da resolução 125/2010, do CNJ. ACTIO Revista de Estudos Jurídicos, Maringá: Faculdade Maringá, n. 23, p. 253-266, 2013.

SALLES, C. A. Negociação, mediação e arbitragem. São Paulo: Método, 2013.

SILVA, S. R. D. da. A mediação como método de resolução de conflitos relacionados à gestão de recursos hídricos no distrito federal. Disponível em: $<$ http://www.ambitojuridico.com.br/site/index.phpn_link=revista_artigos leitura\&artigo_id=6429>. Acesso em: 01 set. 2013.

SIPS. Disponível em: $<$ http://www.ipea.gov.br/portal/images/stories/PDFs/ SIPS/110531_sips_justica.pdf>. Acesso em: 28 ago. 2013.

SILVEIRA, L. Acordos firmados durante Semana Nacional ultrapassam R\$ 700 milhões. Disponível em: <http://www.cnj.jus.br/noticias/cnj/22622acordos-firmados-durante-semana-nacional-ultrapassam-r-700-milhoes $>$. Acesso em: 05 set. 2013.

SCOLESO, F. O surgimento da sociedade de massas. Disponível em: <http:// sala19.wordpress.com/2009/05/30/aula-o-surgimento-da-socidade-de-massas/>. Acesso em: 21 ago. 14.

\section{ACCESS TO JUSTICE IN COMPLEX SOCIAL ORGANIZATIONS AS IMPLEMENTATION OF THE PRINCIPLE OF HUMAN DIGNITY}

ABSTRACT: This article aims to portray the importance of self-composition methods in contemporary society, in order to give the person the opportunity to reflect on the conflict of interests and actively participate in their solution, while providing true social peace. Among the new rights caused by the complexity of the relations of the mass and network society, the principle of human dignity is the basis of the democratic state, also emphasizing the need to ensure, through access to justice, fundamental rights of the individual. It briefly approaches the 
origin of mass and network society, as well as some of the social implications resulting mainly in the alienation of human beings, who, for decades, believed that the Judiciary was the holder of the monopoly of conflict resolution.

KEYWORDS: Access to justice; Principle of human dignity; ADRs.

\section{EL ACCESO A LA JUSTICIA EN LAS ORGANIZACIONES SOCIALES COMPLEJAS COMO CONCRETIZACIÓN DEL PRINCIPIO DE LA DIGNIDAD DEL SER HUMANO}

RESUMEN: Este artículo busca retratar la importancia de los métodos auto compositivo en la sociedad contemporánea, teniendo en cuenta que conceden a la persona la oportunidad de reflejar sobre el conflicto de intereses y participar activamente en la solución de esos, proporcionando una verdadera pacificación social. Entre los nuevos derechos proporcionados por la complejidad de relaciones de la sociedad de masa y red, el principio de la dignidad del ser humano sirve de fundamento para el Estado Democrático de Derecho, creando, también, la necesidad de garantizar, por medio del acceso a la justicia, los derechos fundamentales de la persona. Se discute, brevemente, el origen de la sociedad de masa y de red, así como algunas de sus implicaciones sociales resultando, principalmente, en la alienación del ser humano, que por algunas décadas creyó que el Poder Judiciario fuera el detentor del monopolio de solución de conflictos. PALABRAS CLAVE: Acceso a la justicia. Principio de la dignidad del ser humano. ADRs. 